\title{
An analytic approach to resolving problems in medical ethics
}

\author{
Daniel Candee Center for Moral Education, Harvard University and Boston College School of Nursing \\ Bill Puka Department of Philosophy, Rensselaer Institute
}

\section{Authors' abstract}

Education in ethics among practising professionals should provide a systematic procedure for resolving moral problems. A method for such decision-making is outlined using the two classical orientations in moral philosophy, teleology and deontology. Teleological views such as utilitarianism resolve moral dilemmas by calculating the excess of good over harm expected to be produced by each feasible alternative for action. The deontological view focuses on rights, duties, and principles of justice. Both methods are used to resolve the 1971 fohns Hopkins case of a baby born with Down's syndrome and duodenal atresia.

The past decade has seen a substantial increase in recognising the importance of moral factors in making decisions about patient illness. Along with this recognition has come an increased need for physicians to have a systematic method with which to think about and resolve moral problems in medicine. Several techniques have been developed, reviewed by Callahan (1). However, nearly all of these techniques use the format of open-ended discussion of cases involving problematic moral issues. As such, they typically serve to expand the participants' thinking about moral issues, but they do not necessarily focus on making an actual decision. In this paper, we suggest a method which aims at providing a systematic series of questions an individual must ask in order to arrive at a well-reasoned moral decision. The method, which we will call the analytic approach, borrows certain concepts from traditional theories of ethics, and attempts to apply them systematically to making decisions about current ethical problems.

Traditional moral theories are neither procedures nor decision-making rules. Their chief task has been to explain and justify moral beliefs in order to develop consistency, plausibility, and completeness in our moral views. The needs of explanation and justification which they serve are different from the needs of decision-making. Part of what allows general

\section{Key words}

Moral reasoning; decision-making; euthanasia; neonatal care; medical ethics. principles of explanation to be meaningful is a conscious ignoring of the peculiarities of each situation. However, while moral theories are meant to be fundamental and abstract, their principles might, at least, be used as conceptual aids in making moral decisions. This may move us part of the way down the decision-making path in a manner that is more comprehensive and well-reasoned than is opinion or intuition.

Broadly speaking, moral thought traditionally takes two general approaches to answering the basic question in normative ethics, 'What is the right thing to do?' The first approach, teleology usually defines 'right' in terms of the good produced as the consequences of an action. The most prominent form of teleology, utilitarianism, bids one calculate the probable results of performing various actions relevant to a situation and choose one that will maximise the ratio of benefit over harm produced. The second major approach, deontology, defines 'right' by considering intrinsic features of an action, largely independent of its consequences. We will draw on three main concerns of deontological theory here: 1) fulfilling one's duties in a situation, 2) respecting the rights and autonomy of others (regardless of the consequences), and 3) treating others with equal justice. These concerns are organised usefully in the logic of Kant's categorical imperative and principle of respect. Roughly these direct us to act only on rationales that we can generalise to similar situations and which can be consented to rationally by anyone similarly situated (or affected by such actions). Put another way, they advise us to respect everyone's capacity to determine and pursue her or his goals, never treating people as mere means or tools to our ends.

Despite their differences, both orientations are accepted by moral philosophers as worthy of serious consideration. Both strive to be logical, internally consistent, and to yield similar decisions in morally similar situations. Just as theories of natural science strive to explain the natural world by a set of interrelated logical principles, so ethical theories strive to explain the moral world by constructing their own principles.

In order to demonstrate how these two major types of moral theory might be used to resolve a bioethical 
problem, let us consider a particular situation. (We make no pretence at presenting an orthodox version of either type of theory since neither was designed as a decision mechanism. Further, the extensive variations within each type prevent any one approach from being properly representative of either.) Our goal is to suggest two broad sets of concerns (utility and justice) that must be considered in making moral decisions of any kind. These concerns correspond to those that have distinguished the two major approaches to moral philosophy through the ages.

In 1971 at Johns Hopkins Hospital, a baby was born who, shortly after birth, was clinically diagnosed to have Down's syndrome (mongolism), a condition associated with mental retardation. An additional confirmation of the clinical diagnosis through chromosomal analysis, which takes several weeks to perform, was not carried out. The baby also had duodenal atresia, a constriction of a portion of the intestine that prevents the passage of food. It is fatal if not surgically corrected. Surgery for this condition carries a relatively small risk.

The mother of the baby, a nurse, was so distressed on learning the diagnosis, that she refused to give consent for the operation to remove the intestinal blockage. Her husband accepted the decision, believing that as a nurse, his wife was more knowledgeable about this matter than he. The physician in the case indicated to the parents that children with Down's syndrome often had IQs of between 50 and 80, could perform simple jobs, were usually happy, and could live a long time. This failed to change their minds. The doctors at the hospital did not attempt to thwart the parents' decision through a court order. In the hospital, after about two weeks, the child died of starvation (2).

Were the doctors at Hopkins right or wrong to have allowed the baby to starve? We begin resolving the dilemma by consulting the process of moral decisionmaking outlined in Table 1 . The first step according to both the utilitarian and the deontological viewpoints is to gather claims, ie, to determine who wants what. As a practical matter, we will have to limit the scope of persons whose interests can be considered. Among those persons who will be directly affected by the present decision are the parents, who would like to avoid the difficulty of rearing a retarded baby, the doctors, who are willing to accede to the wishes of the parents, and the baby who, we can assume, would like to live as normal a life as possible.

Step two, determining feasible alternatives, is greatly influenced by the presentation of claims. Within limits set by the environment, we can usually act in a way that satisfies the exclusive claims of either party or partially satisfies the claims of both. The purpose of moral decision-making is to determine which of the feasible alternatives is morally best. In the present case, the alternatives would seem to include performing surgery, allowing the baby to die (passive euthanasia), or actually ending the baby's life (active euthanasia).

\section{Utilitarian approach}

At step three, utilitarian and deontological approaches diverge. Deontology determines the most moral action by setting forth the rights, duties, and principles involved in a situation and by trying to determine which take precedence. By contrast, utilitarian theory determines which actions will lead to the greatest ratio of benefit to harm for all persons involved in a dilemma. (This can be done for each act or by formulating a rule which, if followed regularly in similar situations, would be likely to maximise good.) In order to calculate the utilitarian ratio it is necessary to predict the possible outcomes (consequences) of each action, the probability of each outcome occurring, and the desirability of those outcomes for the child and for the parents and for society (Table 1 , steps 3-6). The presentation of the utilitarian approach will rely heavily on the method outlined in Brody (3).

Three possible outcomes are considered for each alternative action. These range from the best to the worst possible results measured in terms of the goal that a particular alternative was designed to achieve. The feasible alternatives, predicted outcomes and associated probabilities are the same from the perspective of both parents and child. They are presented in Table 2 , columns 1 and 2 , and are repeated in Table 3, columns 1 and 2. The outcomes from the perspective of society differ, as we shall see shortly.

\section{Table 1: Steps in the moral reasoning process}

\section{Teleological (Utilitarian) approach}

1) Gather general claims

2) List feasible alternatives

3) Predict consequences (outcomes) of each action

4) Determine probability of each outcome occurring

5) Assign value to each outcome (determine basis of valuing)

6) Determine utilities (probability multiplied by the ascribed value of the various outcomes)
Deontological approach

1) Gather general claims

2) List feasible alternatives

3) List relevant rights-claims, duties and principles

4) Establish validity of rights-claims

5) Determine priorities and balance claims 
Table 2: Utility of alternative medical treatments (Child's perspective)

Alternative treatment Outcome Probability

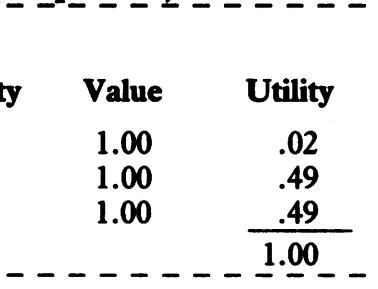

Alt Value Alt

\begin{tabular}{|c|c|}
\hline Surgery & $\begin{array}{l}\text { Normal IQ } \\
60 \mathrm{IQ} \\
40 \mathrm{IQ}\end{array}$ \\
\hline thes & Total utility \\
\hline $\begin{array}{l}\text { Passive } \\
\text { euthanasia }\end{array}$ & $\begin{array}{l}\text { Die quickly } \\
\text { Die slowly } \\
\text { Die very slowly } \\
\text { and painfully } \\
\text { Total utility }\end{array}$ \\
\hline $\begin{array}{l}\text { Active } \\
\text { euthanasia }\end{array}$ & $\begin{array}{l}\text { Die quickly } \\
\text { Die slowly } \\
\text { Die very slowly } \\
\text { and painfully } \\
\text { Total utility }\end{array}$ \\
\hline
\end{tabular}

\section{.02}

.10

.80

.10

.30
.10
.00
.30
.10
.00

.30

.10

.00

.03

.08

.00
Looking at Table 2, we see that the best outcome if surgery is done is that the child will be intellectually normal. However, the probability of this event occurring has been estimated to be only two chances out of 100 . Indeed, the best outcome will occur only if the initial diagnosis, which was not checked by chromosomal analysis, was in error. Probability estimates are made on information derived from either an experienced person, or preferably, the research literature. In this case, studies reviewed by Rynders, Spiker, and Horrobin (4) have established that a randomly chosen baby who has been correctly diagnosed as having Down's syndrome will have an equal chance of developing an IQ in the range of 30 to 50 as it will of developing one in the range of 50 to 80 . Since we are allowing for the two per cent chance that the child will be normal, we will consider the likelihood of the less desirable outcomes occurring to be .49 each.

Similarly, the probability that each of the other outcomes listed in Table 2 will occur can also be estimated. Where research literature or an experienced person is not available (as in predicting the probability of a baby dying quickly without food), an educated guess (based, perhaps, on related experiences) must be made. In medicine, as in all fields, actions must sometimes be taken with far less than perfect knowledge of the resulting consequences. However, to make no estimate at all substitutes prejudice and happenstance for rationality.

Up to this point, we have simply analysed the moral problem and assembled relevant data. We have made no value judgements. The fourth step in the utilitarian approach is to assign values to each possible outcome. In the present problem, we must consider the 'value' of life for a retarded person. How does living with an IQ of 60 , for example, compare to living with a normal IQ,

\section{with an IQ of 40 , or not living at all?}

The answer to these questions depends largely on whose viewpoint is being taken. It might seem natural to start with the child's viewpoint, but can a neonate, much less a retarded one, assess the 'value' of life? This situation reveals an issue that must be addressed whenever one is calculating utilities. Should we consider the subjective value of a behaviour to an individual, or make a more objective assessment of what that behaviour is worth?

In the present case, there are three main reasons for considering the full subjective value of behaviour to the child. Perhaps most important is the common observation that retarded persons of any age do not find living painful in itself and give no indication that they would prefer to die. Moreover, just as the positive joys of life are limited for retarded people, so are the sorrows. On balance, a retarded person might find his or her life as pleasurable as a mentally normal person. Lastly, since the other people in the dilemma are adults, they have only a part of their lives ahead of them. In comparison, the neonate has its entire life ahead.

The argument for limiting the value of the child's life rests on a more 'objective' or 'comparative' approach. Using this approach we leave the particular neonate's perspective and compare the life of a retarded person to that of a normal individual. Since the retarded person cannot experience the full range of human reactions, the quality of his or her life activities seems diminished. Retarded persons themselves often recognise that much is missing in their experiences. Thus, if the goal of utilitarianism is to produce the greatest overall good, then by this reasoning, the life of the retarded neonate should be counted less than the life of a fully functioning adult. 
There can be no resolution of this issue within the scope of this paper. Both arguments have merit. Some readers will undoubtedly favour the subjective approach, others will favour the objective one. What we wish to emphasise here is that no matter which solution is ultimately chosen, all persons at this point in the utilitarian calculation must address the question: 'value of behaviour to whom?' in assigning value to behaviour.

In order to demonstrate that the steps in the utilitarian process are the same regardless of which values are assigned we will go through the solution twice, first choosing values that stem from the subjective viewpoint, then choosing values stemming from the objective point of view. From the subjective viewpoint the value of life, as seen on behalf of a severely retarded child, will be immense. We may quantify this value judgement by giving the outcomes of living with either a normal, a $60 \mathrm{IQ}$, or a $40 \mathrm{IQ}$ a weight of 1.0 on a scale of zero to one (Table 2 , column 3).

In comparison to the outcomes for surgery, the possible outcomes for euthanasia are much less desirable, when assessed on behalf of the child. Clearly, the worst outcome would be to die slowly and painfully. This outcome can be given a value of zero (Table 2, passive euthanasia, column 4). In comparison, the prospect of dying slowly and with less pain is a slightly more palatable choice. Thus, our 'rational infant' may give it a valur of .10. However, the prospect of a quick and pain-free death should be the least objectionable euthanasia outcome and may be valued even higher, say .30 , by the child.

Based on the probabilities and values assumed in Table 2, we are now able to calculate the total utilities for each feasible alternative. This is done by multiplying the value of each possible outcome by its associated probability and then summing across outcomes within each alternative. The resulting utilities are contained in the fifth column of Table 2 . As shown, performing the atresia operation is, from the child's subjective point of view, of much greater utility than either of the other two choices.

Now let us shift ground for a moment and assume that a reasoner takes an 'objective' view of the value of life. In that case, the values assigned to the outcomes of living with an IQ of 60 or 40 will be much lower. Such values are listed under the 'alternative value' column in Table 2. They reflect the fact that, objectively, the quality of life for a mentally disabled person is considerably less than for a person of normal intelligence. The utility of each outcome given the 'alternative value' is that value multiplied by the probability of the outcome occurring. The probabilities remain as they were in column 3 . The new 'alternative utilities' are given in Table 2, column 6.

The particular values a person chooses depend on his or her philosophical and religious beliefs and on his or her perception of the world. However, what binds together all persons who solve the dilemma in the spirit of consequentialism is that all will follow the same logic and all will have to wrestle with the same philosophical and factual problems.

Regardless of which set of utilities is accepted in Table 2, the child's point of view is only one among several that should be considered. Table 3 presents the utilities of each outcome from the viewpoint of the parents. The first question which arises here is whether the parents' perspective should carry twice as much weight as the child's. A strict utilitarian approach would count each person's utilities equally. Thus, if there are two parents their combined perspective would carry twice as much weight as the child's. However, from a functional point of view the parents act in unison, not in isolation. It is easier for one parent to rear a retarded child if he or she has the help of the other. For this reason, it makes sense to treat the parents' perspective as one.

The situation can be handled statistically by considering the value of each outcome under the parents' perspective as the interaction of the value of that outcome to each parent alone. For example, we might estimate the value of rearing a child with an IQ of 60 to be .55 for each individual parent. The interaction would, therefore, be .55 (value to one parent $) \times .55$ (value to other parent $)=.30$ (value from parents' perspective). It is this figure (.30) that appears as the value for the second outcome under surgery on Table 3.

In practice, what we are suggesting is that instead of estimating the value to each parent individually the value from the parents' perspective be estimated directly. Where individuals act as a functional group it seems best to assign values in terms of that group. This technique will be especially helpful when we consider the effect of each alternative on society.

Returning to Table 3, surgery, we see that while the prospect of having a child with an IQ of 60 is a lowly valued outcome (.30) the prospect of caring for a youngster with an IQ of 40 is valued even less. As for euthanasia alternatives, the outcome of dying quickly would seem to be valued about the same as that of dying slowly. While the former involves less pain to the child, the latter may be perceived by the parents as removing some of the responsibility for the baby's death from their shoulders. As before, the parents would place no value on the prospect of a painful death for their child. Notice that while the value weightings changed considerably from Table 2 (child's viewpoint) to Table 3 (parents' viewpoint) the probabilities remained the same. Value judgements may be different for each moral reasoner. Probabilities, within limits set by consulting different sources of information, are not.

Again, as we did for the child's perspective, we present alternative utilities based on parents who might posit different values for rearing a mentally defective child. Columns 6 and 7 of Table 3 present alternative values and utilities for parents who give no value to rearing a child whose IQ is significantly less than normal. Again, our point is not to advocate one 


\section{Table 3: Utility of alternative medical treatments}

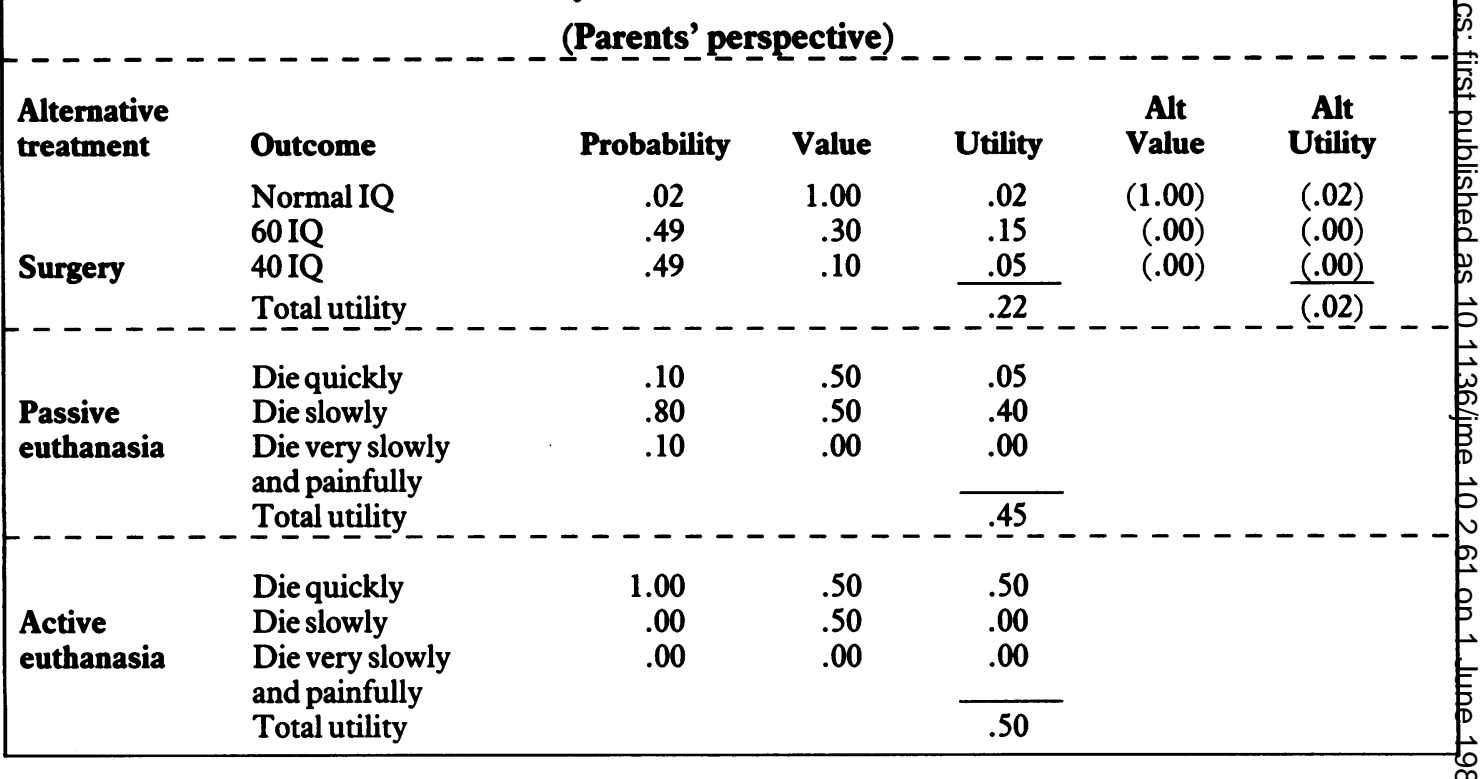

solution or the other but to demonstrate the process of utilitarian reasoning.

In addition to the parents' and child's perspectives, a third perspective, that of society, may also be considered. While society consists of millions of individuals, it may be better to treat them as a unit. After all, individuals will not be directly involved in paying for or caring for a child who may be institutionalised or may need special services. Those decisions will be made in the name of society by agency officials. It matters little to any single member of society whether a normal child is added to the rolls of a public school or to the rolls of an institution for the mentally disabled. The impact comes only on the level of a national or community budget.

Again, the idea of treating groups as an interaction of individuals seems to make sense. A very slight difference in value to any single individual between adding a normal or disabled child to the world (for example, 1.0 vs 0.99 ) will become meaningful when each figure is multiplied exponentially by the number of people in society. Rather than trying to perform this elaborate calculation we again recommend estimating the value of each outcome directly from the viewpoint of society. The values for the three surgery outcomes are shown in the first three rows of Table 4 (overleaf). The cumulative effect of the difficulties that would fall upon a society having to provide for a mentally disabled child can be seen in the dramatically lower value given to the 60 and 40 IQ outcomes compared to the normal IQ outcome. The lower values reflect the cost of special services and possible institutionalisation for the child.

When we turn to the euthanasia outcomes we notice that the possible outcomes have changed from Tables 2 and 3. What does it mean for society to be concerned with the outcome of this particular child dying? The effect would seem to lie in the consequences that this case would have for other similar cases. Thus, the besis we could hope for under the passive euthanasio alternative would be that this case would set f $^{2}$ precedent allowing persons who have good reason to 8 die to do so. As previously discussed, the value of setting a precedent which would allow for a quick death (outcome 1 under both the passive and actives euthanasia alternatives) and a slow death (outcome 2) is about the same (.5). However, as was true in Tables 2. and 3 , the probability of active euthanasia leading to quick death is much greater than it is for passives euthanasia. The most interesting outcome of the euthanasia alternatives is outcome 3 , the possibility that the guidelines established by the present case maye prove inadequate to distinguish between euthanasia that is in the patient's best interest from cases wheres it is not. One of the greatest public fears concerning euthanasia is that persons who may want to be saved will be allowed to die. This is another version of the 'slippery slope' argument. The purpose of presenting if here is to recognise the worst danger entailed by euthanasia and to estimate the probability of itso occurrence as a consequence of either the passive active euthanasia approaches. As can be seen in Table 4 (outcome 3), we consider the risk of inappropriate guidelines to be greater in the case of active euthanasiad than in the case of passive euthanasia. There is more risk of committing an error that cannot be undone if active euthanasia is used. Thus, despite the relief in suffering that active euthanasia may provide to a given individual it is a riskier and hence less usefur alternative from society's point of view. Howevero compared to surgery and the likelihood that a mentalle. disabled child will be added to the world both forms of 
Table 4: Utility of alternative medical treatments (Society's perspective)

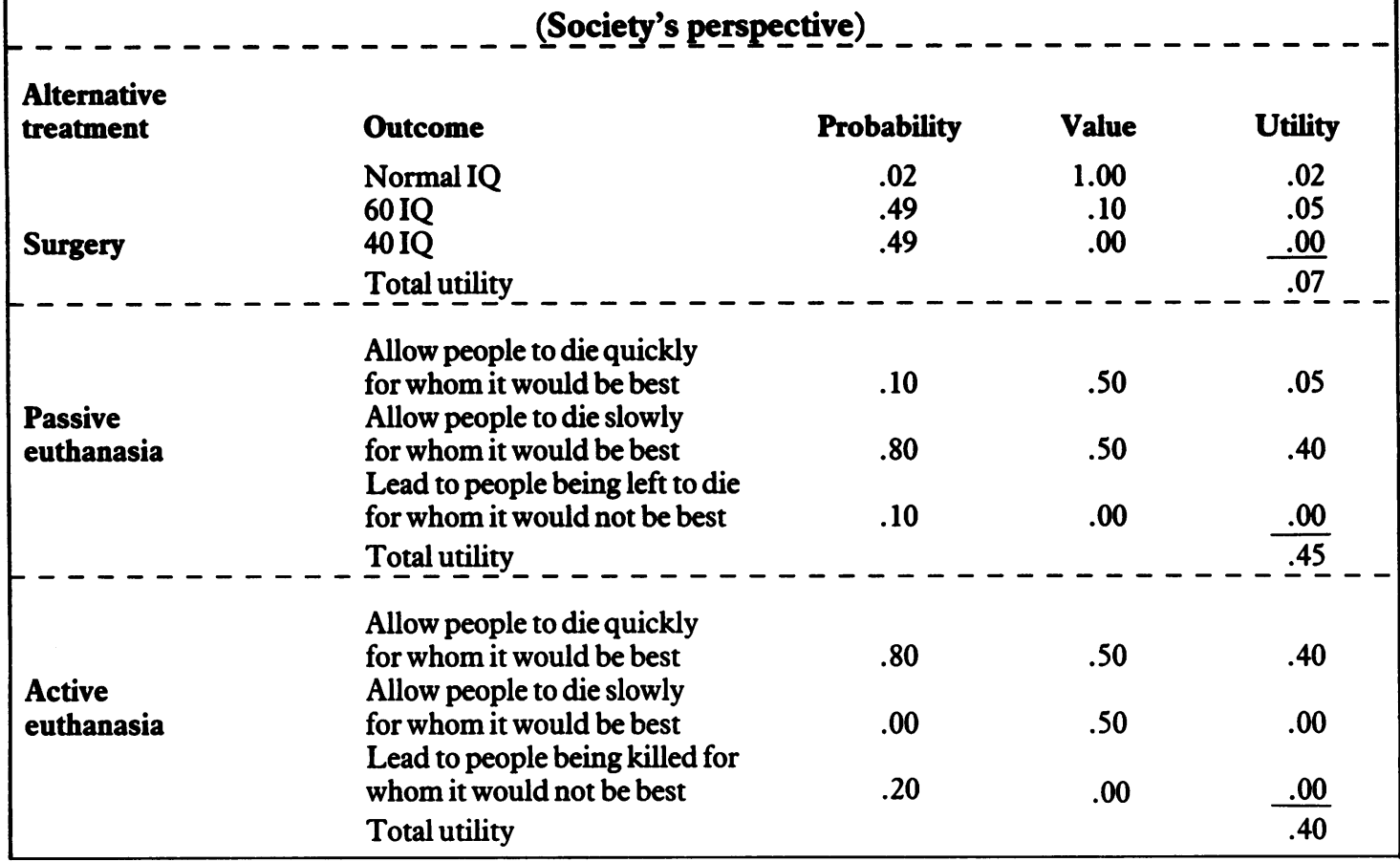

euthanasia are more desirable.

The final step in the utilitarian approach is to combine the total utilities for each alternative as seen by the parents, by the child, and by society. Doing so (Table 5) reveals that, given the probabilities and original set of values, surgery is the most useful option. This is due primarily to the clear advantage that the opportunity to live has for the child, even though it is recognised that the child will almost certainly be mentally disabled. In comparison, the disadvantages of surgery to the parents and to the society are not as great.

However, if we accept the alternative utilities shown in Table 5, we arrive at a different conclusion. A comparison of these utilities indicates that euthanasia, particularly active euthanasia, is the preferred choice. The change between the two sets of utilities in Table 5 rests primarily on the value that the child himself would give to living with an IQ significantly below normal. If that value is high, then the surgery alternative has great utility (see child utility column). If it is not, then the surgery alternative becomes least attractive. A smaller but still significant change between the original and alternative utilities is the contribution made to the surgery alternative by the parents. If the parents find some value in rearing a

Table 5: Utility of alternative medical treatments (Combined perspectives)

Alternative
treatment


mentally disabled child (as in the original utilities) then the surgery alternative is more likely to be useful. If they do not (as in the alternative utilities) then the surgery alternative becomes less useful.

\section{Deontological approach}

Having considered a teleological approach to solving the dilemma, let us now turn to the perspective of deontology. As stated earlier, deontology denies what teleology asserts. That is to say, in the deontological perspective, the moral rightness of an act is determined not by the consequences it produces, but by qualities intrinsic to the act itself. The particular qualities that we will consider here are the basic human rights and duties that impinge on a situation. We shall organise our thinking about the deontological approach around two questions: 'What rights are claimed, and by what principles are they valid?', and 'What duties are owed by whom and to whom?' (Table 1, steps 3 and 4).

In answer to the first question, three rights-claims seem relevant to this situation: the child's claim to life, the parents' claim to liberty in their own lives, and the parents' claim to the freedom of being able to make decisions affecting their child.

We will look first at the child's claim of having a right to life. On what basis should we recognise this right? There is, of course, no simple answer. It is often argued that rights are associated with the status of personhood. But how is personhood defined? It seems reasonable to us that, since personhood is being used as a moral category here, to qualify as a person an individual must have the essential characteristics that distinguish us as a species capable of morality. These characteristics include the capacity to prefer one set of goods over another and the capacity to be treated and to treat others with respect or concern. Further, there must be a sense of self or at least a sense of being alive. Together, these characteristics constitute having ' $a$ point of view'. To speak of a rights-claim presumes that ignoring that claim would cause a significant harm to, or loss or infringement of that individual's point of view.

It is difficult to determine whether a retarded neonate qualifies as a person by these criteria. Some of the difficulty is simply due to the child's status as a neonate. Are its faculties cognitively or subjectively complex enough to represent a 'point of view'? The neonate may discriminate pleasant from unpleasant stimuli, but does it really care about the difference? Further complications are caused by the problem of mental retardation. Will the retarded neonate ever develop a sufficient sense of self?

There is no doubt that the retarded neonate can be a recipient of moral concern, that she or he is a moral person in this respect. Yet, can he or she function even as a minimally active moral participant - showing respect, honouring rights, and fulfilling duties? A small animal can be trained to obey rules and we may be duty-bound to care about its welfare, but to have a right to life (a claim against even being painlesslym killed) one may have to be able to reciprocate in $\overline{\overline{0}}$. practices of mutual respect. In this way, arguments can? be made both for and against according the child the right to life. While we suspect that most moral ? reasoners will support the pro-right position in this situation, it also may be argued that the child only has $\frac{\overline{\bar{n}}}{\text {. }}$ a right not to be harmed. Neither right in itself leads $\frac{\mathbb{\Phi}}{\overparen{D}}$ inexorably to only one treatment alternative. The stance taken here may lead to either surgery ores euthanasia depending on how one assesses all of the $\overrightarrow{0}$ right-claims taken together.

The second rights-claim we should consider $\vec{\sigma}$ concerns the parents' liberty. Clearly, rearing a retarded child places especially serious limits on the activities of its parents. It forces them to re-orientate $\overrightarrow{0}$ their lifestyles radically and thus prevents them fromiv exercising their right to liberty fully. In determiningthe validity of that claim, we must first recognise thato the mere curtailment of liberty does not in itself represent a right violation. A right is a claim againstc others interfering unjustly. If the parents have a duty to rear the child, then the interference is justified. $\rightarrow$ Similarly, the mere fact that the parents may feet constrained to rear the child, once euthanasia is ruled ${ }^{+}$ out, does not constitute a rights violation. So long as? they are not coerced into such an action, their rights ares not violated.

On the other hand, forcing the parents to keep and rear the baby when they have no special duty to do so $\frac{\mathbb{Q}}{2}$ would violate their rights. To determine if this is the $\overrightarrow{\vec{F}}$ case let us proceed with the third and fourth steps in 3 the determination of duties.

The relevant duties seem to be from the parents andọ from society toward the child. (We will ignore the possibility, because it is slim, that the child has duties to commit suicide or seek foster care to avoido burdening its parents. After all, it did not bring itself of? its disabilities into existence or into its parents' lives.) $\stackrel{\hat{\rho}}{0}$

Considering the parents first, there is a generally recognised special duty of parents to sustain the lives of their children. But does this duty extend to sustaining the life of a retarded neonate? The major argument for extending the duty is based on the fact that the parents brought the child into the world as a dependant. There are generally recognised practices in this cultures pertinent to the nuclear family which many would argue include rearing retarded children. Assuming that the parents knew what these expectations wereo before the act of conception, they can now be held responsible for fulfilling them. Given this argument, those who also believe the child has a right to life may look to the parents to honour the right by authorising surgery.

Let us now consider the opposite argument, a case against extending the parents' special duty to cover thiso situation. Such an argument might contend that the special obligation of parents to care for their childreno holds only for such behaviour that can reasonably be expected to accompany parenthood. Since the parents? 
could not reasonably have expected that their child would be born retarded, with accompanying duodenal atresia, they cannot be held fully responsible for sustaining its life. Persons holding this view may concede that the parents have a special obligation to do more for the retarded child than they would be expected to do for a normal child, including purchasing special equipment, providing a special education, and making an extreme effort to find a surrogate home for the child. But, according to this argument, they do not have an ultimate obligation to raise the child personally or to shoulder all the financial burden of having someone else raise the child.

If the parents do not have the ultimate responsibility for rearing the child, who does? If we recognise a general duty to sustain the lives of persons, as do most deontologists, then all members of the community would have an obligation to contribute to raising the child. Often this obligation is discharged by supporting public institutions for the mentally handicapped. However, there may be no efficient mechanism for enforcing this obligation or for maintaining a reasonable quality of life at such institutions. In that case, we may arrive at a situation in which rights and duties are not reciprocal. The child may indeed have a right to life but no one may have a special obligation to make extreme sacrifices in order to sustain that life. In that case, the situation becomes a tragedy for the neonate and he or she may be left to die.

The third rights-claim to consider is the parents' will to determine the fate of their child. The claim takes two forms. One form holds that parents should be allowed to choose any action they consider 'reasonable' for their child. Since this claim rests on the parents' special relationship to the child, it should be limited by their special duty. As we have said, if the parents recognise the child as having a right to life, then their special duty extends at least as far as trying to find some means to sustain that life. The parents may be justified in asserting the freedom to select the nature of that sustenance (for example, natural family, institutionalisation, adoption) but they cannot claim a right to avoid the search entirely and let the child die. Should the search prove unsuccessful, then the parents may be in a position to let the child die simply by refusing to be the only persons to step in and actually sustain the child's life. Notice, though, that if this possibility exists, it would seem to apply only in cases where the child creates certain difficulties that could not reasonably have been expected by the parents before it was born. It is unlikely that an argument could be made for letting a normal child die.

The second form of the parents' claim holds that regardless of the wisdom of their views, no other party has a greater right to determine the fate of their child than they do. Again, the claim rests on the special relationship of parent and child. But, in this case, the doctors also have a special relationship with the child, that of doctor and patient. The doctors, too, hold the child's interests in their trust. Thus, while the parents may be justified in asserting that their view should be equal to any other, a further case must be made to show that it is superior. Where the decisions of two parties, each having a special relationship to the child, differ, a third party who is specially equipped for deciding such issues, might be consulted. That party might consist of the courts or of an ethics committee. Of course, the function of that body should not be to decide the case in lieu of persons having special relationships with the child. Rather, it should adjudicate the arguments raised by the specially related persons.

\section{Summary and conclusions}

We have now pursued two approaches to moral decision-making and arrived at both decisions to perform and not to perform the atresia operation on the basis of each of them. In the case of the utilitarian approach, the difference in recommended actions hinged on differences in assigning values to the various alternatives. In the case of the deontological approach the difference hinged on the limits one sets on claims both to rights and to duties. Our goal has not been to convince the reader that one or the other action-choice is correct, but rather to suggest a way in which two broad sets of concerns (utility and justice) can be systematically considered in the course of making moral decisions. In doing so, we selected only certain tenets of each approach. We made simplifying assumptions and knowingly omitted certain content complications. However, we have tried to organise an individual's moral decision-making around certain ordered steps and questions that can readily be applied to solving problems in medical ethics.

The value of such an approach to students in general and to health professionals in particular seems to be three-fold. First, no decision reached through the systematic application of a valid ethical approach will be arbitrary. In the process of our reasoning, we have specified those perceptions of facts that must be made if a decision to perform or not to perform the operation is to be made. Thus, given the same value judgements and the same factual perceptions, all persons using a single ethical approach in a consistent manner should arrive at a similar moral decision in the case. Second, it encourages the health professional to adopt a logical, systematic approach to moral or social problems just as he or she would in solving professional (for example, medical or legal) ones. Third, the use of systematic thinking increases the chances that the decision the reasoner finally reaches will be both consistent with the reasoner's own values and in the best interests of the client.

An individual may not actually go through the process of constructing utilitarian tables or listing all claims, rights, and duties in every moral dilrmma. A simple list of pros and cons, and a consideration of one or two rights will probably suffice in most cases. But, having seen the process that underlies detailed ethical reasoning, the health professional is in a better position 
to guide her thought and to know which questions must be answered before she or he can rest comfortably with any moral decision.

\section{Authors' note}

This work was supported by the Department of Pediatrics, State University of New York Downstate Medical Center, where the first author was an Assistant Professor, 1977-1978.

Requests for reprints should be addressed to Daniel Candee, Larsen Hall, Harvard University, Cambridge, Ma, 02138, USA, or to Bill Puka, Department of Philosophy, Rensselaer Institute, Troy, NY, 12181, USA.

\section{References}

(1) Callahan D. The teaching of ethics in higher education: a report by the Hastings Center. Hastings-on Hudson, NY: Institute of Society, Ethics, and Life Sciences, The Hastings Center, 1980.

(2) Reiser S, Dyck A, Curran W. Ethics in medicine. Cambridge, Mass: MIT Press, 1977.

(3) Brody H. Ethical decisions in medicine. Boston, Mass: Little, Brown \& Company, 1976: Chapter 2.

(4) Rynders J, Spiker D, Horrobin M. Underestimating the educability of Down's syndrome children: examination of methodological problems in recent literature. American journal of mental deficiencies 1978; 5: 440-448.

\section{Commentary}

\section{Charles Fletcher Emeritus Professor of Clinical Epidemiology, University of London}

This paper gives detailed consideration to two separate ethical approaches to deciding on the management of a newborn baby with Down's syndrome and duodenal atresia: the options considered are curative operation; allowing the baby to die with or without control of distress and actively dispatching it either by quick, slow or painfully slow methods. Logical thinking about each of the main approaches teleological (or utilitarian) and deontological (or moral-duty based) is urged along the steps outlined in Table 1. In the utilitarian analysis the reasoning is supported by numerical ratings of the values to baby, parents and society of the alternative actions which are then multiplied by their probabilities of occurrence to derive a 'utility' score for each of them. These are then added up to give a final set of utility scores (Table 5) first adopting a 'subjective' and then an 'objective' view of what the baby's wishes might or should be. In the deontological analysis the rights and duties of the same three parties are considered without any

\section{Key words}

Medical ethics; utilitarianism; deontology; decision-making in medical ethics. numerical transformation. The authors give no guidance about which their own choice of action would be, they simply urge that their logical processes should be followed, suggesting that these are analogous to the processes by which decisions are taken in clinical diagnosis or treatment or in legal thinking. The ultimate decision, they admit, will depend upon individual value judgements. They propose no way of combining the two analyses nor do they suggest which should be given the greater weight.

This advocacy of logical analysis of ethical quandaries is one which will commend itself to many practitioners in the caring professions. But the basis of and detailed prosecution of their analyses are open to criticism.

i) They pay no attention to the consequences of alternative decisions on the members of the clinical team. For them active euthanasia is ruled out if for no other reason by the risk of a charge of murder as in the recent Arthur case in Derby and of the endless legal disputes that have followed such decisions in the USA. The authors admit that their consideration of the particular example they give is not complete (they ignore, for instance, the diminished life expectancy of a baby with Down's syndrome which will reduce the 'values' of preserving its life). Nor do they consider the alternative of having the baby adopted, after surgery, by foster parents with values quite different from those of the parents in this case.

ii) In the utilitarian analysis the numerical transformations of the three main alternative actions seem both spurious and unnecessary. Even if the crude numbers given to the 'values' and the more securely based probabilities are accepted their combination to produce the utilities have little value for comparison with each other without some estimate of their errors, so that significant differences between them could be determined. The bland statement in relation to Table 5 that the utility figure of $\mathbf{1 . 2 9}$ for surgery is 'greater' than 1.20 for active euthanasia is absurd. Without knowledge of the potential errors of these figures they have no more meaning than a 'simple list of pros and cons' which the authors eventually admit 'will suffice in most cases', (but without saying which sort of cases will benefit from a numerical analysis and why). The dramatic change in the eventual utilities brought about by a change from the 'subjective' to the 'objective' view of the baby's valuation of survival shows how insecure these figures are. They also treat the values of the two parents as one. This is of uncertain validity even if they agree, but what if they disagree?

iii) The authors' claim that their proposed method is akin to that used by doctors and lawyers in reaching their opinions is invalid. I do not think doctors ever give numerical values to the values and probabilities of occurrence of the consequences of alternative diagnostic and therapeutic decisions that they take. If they did they would realise that they should work out some statistical technique to enable them to interpret differences between the numbers. 